Article

\title{
Extraction of Proanthocyanidins from Chinese Wild Rice (Zizania latifolia) and Analyses of Structural Composition and Potential Bioactivities of Different Fractions
}

\author{
Mei-Jun Chu ${ }^{1}$, Yong-Mei Du ${ }^{1}$, Xin-Min Liu ${ }^{1}$, Ning Yan ${ }^{1}$, Feng-Zhong Wang ${ }^{2}$ and \\ Zhong-Feng Zhang ${ }^{1, *}$ \\ 1 Tobacco Research Institute, Chinese Academy of Agricultural Sciences, Qingdao 266101, China; \\ chumjun@163.com (M.-J.C.); duyongmei@caas.cn (Y.-M.D.); liuxinmin@caas.cn (X.-M.L.); \\ yanning@caas.cn (N.Y.) \\ 2 Institute of Food Science and Technology, Chinese Academy of Agricultural Sciences, Beijing 100193, China; \\ wangfengzhong@caas.cn \\ * Correspondence: zhangzfng@163.com; Tel.: +86-532-88702239
}

Academic Editors: Mingfu Wang and Yueliang Zhao

Received: 11 April 2019; Accepted: 28 April 2019; Published: 30 April 2019

\begin{abstract}
Due to the importance of proanthocyanidin bioactivity and its relationship with chemical structure, ultrasound-assisted extraction and purification schemes were proposed to evaluate the proanthocyanidin content and analyze the structural composition and potential bioactivities of different proanthocyanidin fractions from Chinese wild rice (Zizania latifolia). Following an optimized extraction procedure, the crude wild rice proanthocyanidins (WRPs) were purified using n-butanol extraction, chromatography on macroporous resins, and further fractionation on Sephadex LH-20 to yield six specific fractions (WRPs-1-WRPs-6) containing proanthocyanidin levels exceeding $524.19 \pm 3.56 \mathrm{mg} / \mathrm{g}$ extract. Structurally, (+)-catechin, (-)-epicatechin, and (-)-epigallocatechin were present as both terminal and extension units, and (-)-epicatechin was the major extension unit, in each fraction. This is the first preparation of WRP fractions with a different mean degree of polymerization $(\mathrm{mDP})$, ranging from $2.66 \pm 0.04$ to $10.30 \pm 0.46$. A comparison of the bioactivities of these fractions revealed that fractions WRPs-1-WRPs- 5 had significant DPPH radical scavenging activities, whereas fraction WRPs- 6 with a high $\mathrm{mDP}$ showed better $\alpha$-glucosidase and pancreatic lipase inhibitory effects. These findings should help define possible applications of WRPs to functional foods or nutraceuticals.
\end{abstract}

Keywords: wild rice; Zizania latifolia; proanthocyanidins; extraction; purification; fractionation; degree of polymerization; bioactivities

\section{Introduction}

Wild rice, the seed of the aquatic plant Zizania (family Poaceae), has long been recognized as a health-promoting whole grain, particularly because of its health benefits, including the ability to suppress oxidative stress, reduce hyperlipidemia, and prevent atherogenesis, type 2 diabetes, and obesity [1-3]. Since wild rice is gluten-free and safe for human consumption, the growing interest in wild rice has increased its commercialization in North America [4]. There are four known species of wild rice. Of these, Z. aquatica, Z. palustris, and Z. texana are indigenous to North America, whereas Z. latifolia is native to China, Japan, and Vietnam [5]. Chinese wild rice (Z. latifolia), which is widely distributed in areas along the Yangtze and Huai Rivers, is an age-old food that has been traditionally used to treat a variety of ailments in Chinese medicinal practice [2,6]. Wild rice is a rich source of phenolic 
compounds including phenolic acids, flavonoid glycosides, and proanthocyanidins. These compounds are the key contributors to the health benefits of wild rice $[4,7,8]$.

Proanthocyanidins, commonly known as condensed tannins, are secondary metabolites that are found in a wide variety of plant-based foods including fruits, vegetables, and grains (e.g., grape, cranberry, litchi, cinnamon, cocoa, and peanut), particularly in the skin and seeds [9-11]. Proanthocyanidins are a class of phenolic oligomers and polymers composed of flavan-3-ol monomer units. The constitutive units are linked through a single bond between $\mathrm{C}-4$ of the upper unit and C-6 or C-8 of the lower unit (B-type), which can coexist with an additional bond between adjacent flavan-3-ol units that connects C-2 of the upper unit via an oxygen atom to C-7 or C-5 of the lower unit (A-type) [10]. In recent years, the demand for proanthocyanidins has increased [9], since proanthocyanidin-rich diets are associated with a reduced risk of chronic cardiovascular diseases, including hypertension and dyslipidemia [12]. Additionally, proanthocyanidins derived from other plants have been reported to have remarkable in vitro antioxidant activity, as well as inhibitory effects on $\alpha$-glucosidase and pancreatic lipase [9,13-15]. $\alpha$-Glucosidase is a key enzyme in the digestion of complex carbohydrates, whereas pancreatic lipase inhibitors can suppress triglyceride absorption, leading to potential antiobesity effects. Inhibition of these two enzymes is, therefore, a valid strategy in managing blood glucose level and obesity [16]. We previously revealed a high content of proanthocyanidins in Chinese wild rice [7]. However, in-depth studies on the extraction, purification, and fractionation of wild rice proanthocyanidins (WRPs) have not been reported. The subunit composition, mean degree of polymerization $(\mathrm{mDP})$, and the related antioxidant, antidiabetic, and antiobesity activities of WRPs remain unknown.

The present study aimed to investigate the chemical structure, including subunit composition and $\mathrm{mDP}$, and potential bioactivities of different WRP fractions. For this purpose, crude WRPs were obtained under optimal extraction conditions achieved by response surface methodology (RSM). The active n-butanol fraction was purified and then fractionated by Sephadex LH-20 chromatography to yield several distinct WRP fractions. After acid-catalysis in the presence of phloroglucinol, these isolated fractions were analyzed by ultra-performance liquid chromatography (UPLC) coupled with linear ion trap quadrupole-Orbitrap-mass spectrometry (LTQ-Orbitrap-MS) to provide structural information of the WRPs. Furthermore, the potential antioxidant, antidiabetic, and antiobesity activities as assessed by the in vitro inhibitory effects on DPPH radical, $\alpha$-glycosidase, and pancreatic lipase of the different fractions were examined.

\section{Results and Discussion}

\subsection{Extraction of WRPs}

\subsubsection{Single Factor Experimental Analysis}

Since extraction is the most important step to recover the highest amount of the target compounds from plants [17], a preliminary single factor experiment was conducted to determine the effects of operation parameters of ultrasound-assisted extraction (UAE) on the content of WRPs. According to the experimental results (Figure S1 in the Supplementary Materials), the four most important independent variables at three levels, namely the concentration of aqueous ethanol $(80,90$, and $100 \% ; v / v)$, the liquid-solid ratio $(40,50$, and $60 \mathrm{~mL} / \mathrm{g}$; $v / w)$, the extraction temperature $\left(30,40\right.$, and $\left.50^{\circ} \mathrm{C}\right)$, and the ultrasonic power $(300,350$, and $400 \mathrm{~W}$ ), were selected for optimizing the extraction conditions using RSM based on a Box-Behnken design (BBD).

\subsubsection{Fitting the Model}

The corresponding experimental results for the content of WRPs of each run in BBD are presented in Table S1 in the Supplementary Materials. By applying multiple regression analysis on the experimental data, the equation describing the correlation between WRPs content and the four variables was as follows: 


$$
\begin{aligned}
& Y=6.09+0.80 X_{1}-0.10 X_{2}-0.098 X_{3}-0.075 X_{4}-0.014 X_{1} X_{2}-0.30 X_{1} X_{3}-0.14 X_{1} X_{4} \\
& -0.043 X_{2} X_{3}-0.26 X_{2} X_{4}+0.19 X_{3} X_{4}-1.37 X_{1}^{2}-1.19 X_{2}^{2}-0.25 X_{3}^{2}-0.30 X_{4}^{2}
\end{aligned}
$$

where $Y$ is the WRPs content (mg/g rice); $X_{1}, X_{2}, X_{3}$, and $X_{4}$ represent the coded variables for the concentration of aqueous ethanol, the liquid-solid ratio, the extraction temperature, and the ultrasonic power, respectively.

The data for the analysis of variance (ANOVA) statistical test of the model are shown in Table 1. The small $p$-value $(p<0.0001)$ suggested that the model was highly significant. Meanwhile, a lack of fit $F$-value of 2.88 and an associated $p$-value of 0.1596 implied that there was an excellent agreement between the experimental values and the predicted values. In addition, a determination coefficient $\left(R^{2}\right)$ of 0.9941 and an adjusted determination coefficient (adj $R^{2}$ ) of 0.9882 indicated that there was a satisfactory correlation between the experimental WRPs content and the values predicted by the equation. A high degree of precision and good reliability of the data were demonstrated by a low coefficient of variation $(\mathrm{CV}=2.24 \%$ ). These results suggested that the model works well at predicting WRPs extraction.

Table 1. Analysis of variance for the fitted model of BBD.

\begin{tabular}{cccccc}
\hline Source & Sum of Squares & Degree of Freedom & Mean Square & F-Value & $p$-Value \\
\hline Model & 27.15 & 14 & 1.94 & 168.10 & $<0.0001^{*}$ \\
$\mathrm{X}_{1}$ & 7.74 & 1 & 7.74 & 670.94 & $<0.0001^{*}$ \\
$\mathrm{X}_{2}$ & 0.13 & 1 & 0.13 & 11.00 & $0.0051^{*}$ \\
$\mathrm{X}_{3}$ & 0.12 & 1 & 0.12 & 10.00 & $0.0069^{*}$ \\
$\mathrm{X}_{4}$ & 0.07 & 1 & 0.07 & 5.83 & $0.0300^{*}$ \\
$\mathrm{X}_{1} \mathrm{X}_{2}$ & $7.78 \times 10^{-4}$ & 1 & $7.78 \times 10^{-4}$ & 0.067 & 0.7989 \\
$\mathrm{X}_{1} \mathrm{X}_{3}$ & 0.35 & 1 & 0.35 & 30.53 & $<0.0001^{*}$ \\
$\mathrm{X}_{1} \mathrm{X}_{4}$ & 0.08 & 1 & 0.08 & 6.80 & $0.0206^{*}$ \\
$\mathrm{X}_{2} \mathrm{X}_{3}$ & $7.30 \times 10^{-3}$ & 1 & $7.30 \times 10^{-3}$ & 0.63 & 0.4396 \\
$\mathrm{X}_{2} \mathrm{X}_{4}$ & 0.27 & 1 & 0.27 & 23.00 & $0.0003^{*}$ \\
$\mathrm{X}_{3} \mathrm{X}_{4}$ & 0.14 & 1 & 0.14 & 11.94 & $0.0039^{*}$ \\
$\mathrm{X}_{1}{ }^{2}$ & 12.23 & 1 & 12.23 & 105.89 & $<0.0001^{*}$ \\
$\mathrm{X}_{2}{ }^{2}$ & 9.17 & 1 & 9.17 & 79.41 & $<0.0001^{*}$ \\
$\mathrm{X}_{3}{ }^{2}$ & 0.41 & 1 & 0.41 & 35.66 & $<0.0001^{*}$ \\
$\mathrm{X}_{4}{ }^{2}$ & 0.57 & 1 & 0.57 & 48.97 & $<0.0001^{*}$ \\
Residual & 0.16 & 14 & 0.012 & - & - \\
Lack of fit & 0.14 & 10 & 0.014 & 2.88 & 0.1596 \\
Pure error & 0.02 & 4 & $4.92 \times 10^{-3}$ & - & - \\
Cor total & 27.31 & 28 & - & - & - \\
\hline
\end{tabular}

\subsubsection{Optimization of Extraction Conditions}

Three-dimensional surface plots were used to explain the interactions of the variables and to determine the optimal level of each independent variable to produce a maximal response. When the extraction temperature and ultrasonic power were set at zero level, the WRPs content increased initially as the concentration of aqueous ethanol and the liquid-solid ratio increased and then slightly decreased (Figure 1A). Similar effects on WRPs content of other variables are shown in Figure 1B-F. The results were in accordance with the single factor experiment and the ANOVA analysis. The maximum predicted value of WRPs content $(6.28 \mathrm{mg} / \mathrm{g}$ rice) could be obtained under the following optimal conditions: a concentration of aqueous ethanol of $93.73 \%$, a solid-liquid ratio of $50.07 \mathrm{~mL} / \mathrm{g}$, an extraction temperature of $44.39{ }^{\circ} \mathrm{C}$, and an ultrasonic power of $330.34 \mathrm{~W}$. Considering the operability in actual processing procedures, a verification experiment was carried out under the following modified conditions: a concentration of aqueous ethanol of $94 \%$, a solid-liquid ratio of $50 \mathrm{~mL} / \mathrm{g}$, an extraction temperature of $44{ }^{\circ} \mathrm{C}$, and an ultrasonic power of $330 \mathrm{~W}$. Under these conditions, the WRPs content of the extract from the verification experiment was $6.33 \pm 0.10 \mathrm{mg} / \mathrm{g}$ rice, which was in good agreement with the predicted value. 

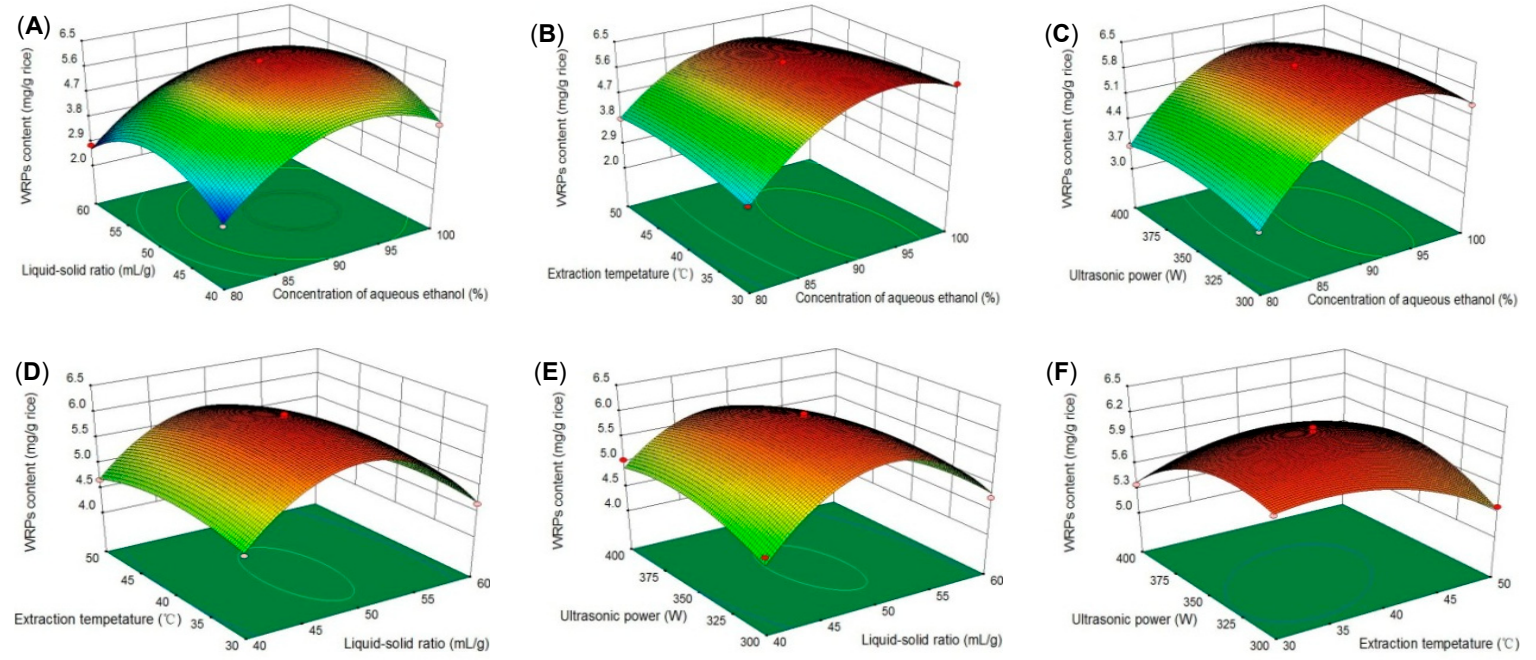

Figure 1. Response surface plots showing interaction effects of concentration of aqueous ethanol and liquid-solid ratio (A), concentration of aqueous ethanol and extraction temperature (B), concentration of aqueous ethanol and ultrasonic power (C), liquid-solid ratio and extraction temperature (D), liquid-solid ratio and ultrasonic power $(\mathbf{E})$, extraction temperature and ultrasonic power $(\mathbf{F})$ on the WRPs content.

\subsection{Proanthocyanidin Content and In Vitro Bioactivities of the Isolated Fractions}

The crude WRPs obtained under the optimal UAE condition were first divided into four fractions soluble in n-hexane, ethyl acetate, $\mathrm{n}$-butanol, and water, respectively. The proanthocyanidin content, DPPH radical scavenging activity, and $\alpha$-glucosidase inhibitory activity were evaluated to determine the active fractions. As shown in Figure 2A-C, the n-butanol fraction had the highest proanthocyanidin content, DPPH radical scavenging activity, and $\alpha$-glucosidase inhibitory activity.

The active n-butanol fraction was then further loaded onto a D101 macroporous adsorption resin column to obtain four fractions (fractions $\mathrm{C} 1-\mathrm{C} 4$ ), which were screened for their proanthocyanidin content, antioxidant activity, as well as $\alpha$-glucosidase and pancreatic lipase inhibitory activities. As shown in Figure 2D-F, the fractions C2 and C3, with the highest proanthocyanidin contents of $282.24 \pm 2.07$ and $112.80 \pm 1.55 \mathrm{mg} / \mathrm{g}$ extract, respectively, displayed good DPPH radical scavenging activity and $\alpha$-glucosidase inhibitory activities. The proanthocyanidins were, therefore, mainly distributed in fractions C2 (10-30\% ethanol effluents) and C3 (40-60\% ethanol effluents), which were combined and concentrated for next fractionation. All the four fractions at a concentration of $10 \mathrm{mg} / \mathrm{mL}$ showed no obvious inhibitory activity against pancreatic lipase.

To further study the structure and in vitro bioactivities of WRPs, the proanthocyanidin-rich fractions (fractions C2 and C3) were fractionated on a Sephadex LH-20 column to obtain six fractions (fractions WRPs-1-WRPs-6), which were measured for the proanthocyanidin content, DPPH radical scavenging activity, as well as $\alpha$-glucosidase and pancreatic lipase inhibitory activities. As can be seen in Table 2, all the isolated fractions had high proanthocyanidin contents, exceeding $524.19 \pm 3.56 \mathrm{mg} / \mathrm{g}$ extract, with fraction WRPs-3 having the highest level of $863.81 \pm 8.02 \mathrm{mg} / \mathrm{g}$ extract. The scavenging effects on DPPH radical were in the order: WRPs- $3 \approx$ WRPs- $4 \approx$ WRPs- $5>$ WRPs- $2>$ WRPs- $1>$ ascorbic acid $>$ WRPs-6. For $\alpha$-glucosidase inhibitory activities of the six fractions, the two fractions WRPs- 5 and WRPs-6 exhibited excellent inhibitory effect with $\mathrm{IC}_{50}$ values of $117.72 \pm 1.45$ and $84.01 \pm 0.74 \mu \mathrm{g} / \mathrm{mL}$, respectively, lower than that of acarbose $\left(\mathrm{IC}_{50}=186.31 \pm 1.04 \mu \mathrm{g} / \mathrm{mL}\right)$. In the pancreatic lipase assay, fractions WRPs-1-WRPs-5 displayed no obvious inhibitory activities $\left(\mathrm{IC}_{50}>2000 \mu \mathrm{g} / \mathrm{mL}\right.$ ), whereas fraction WRPs-6 showed a weak inhibitory effect on pancreatic lipase $\left(\mathrm{IC}_{50}=1054.01 \pm 6.67 \mu \mathrm{g} / \mathrm{mL}\right)$.

These data suggested that the fractions WRPs-1-WRPs- 5 had significant DPPH radical scavenging abilities, whereas fraction WRPs- 6 showed potent $\alpha$-glucosidase and mild pancreatic lipase inhibitory activities. The present fractionation can filter out effective in vitro antioxidants (fractions WRPs-1-WRPs-5) and $\alpha$-glucosidase and pancreatic lipase inhibitors (fraction WRPs-6) to some extent. 

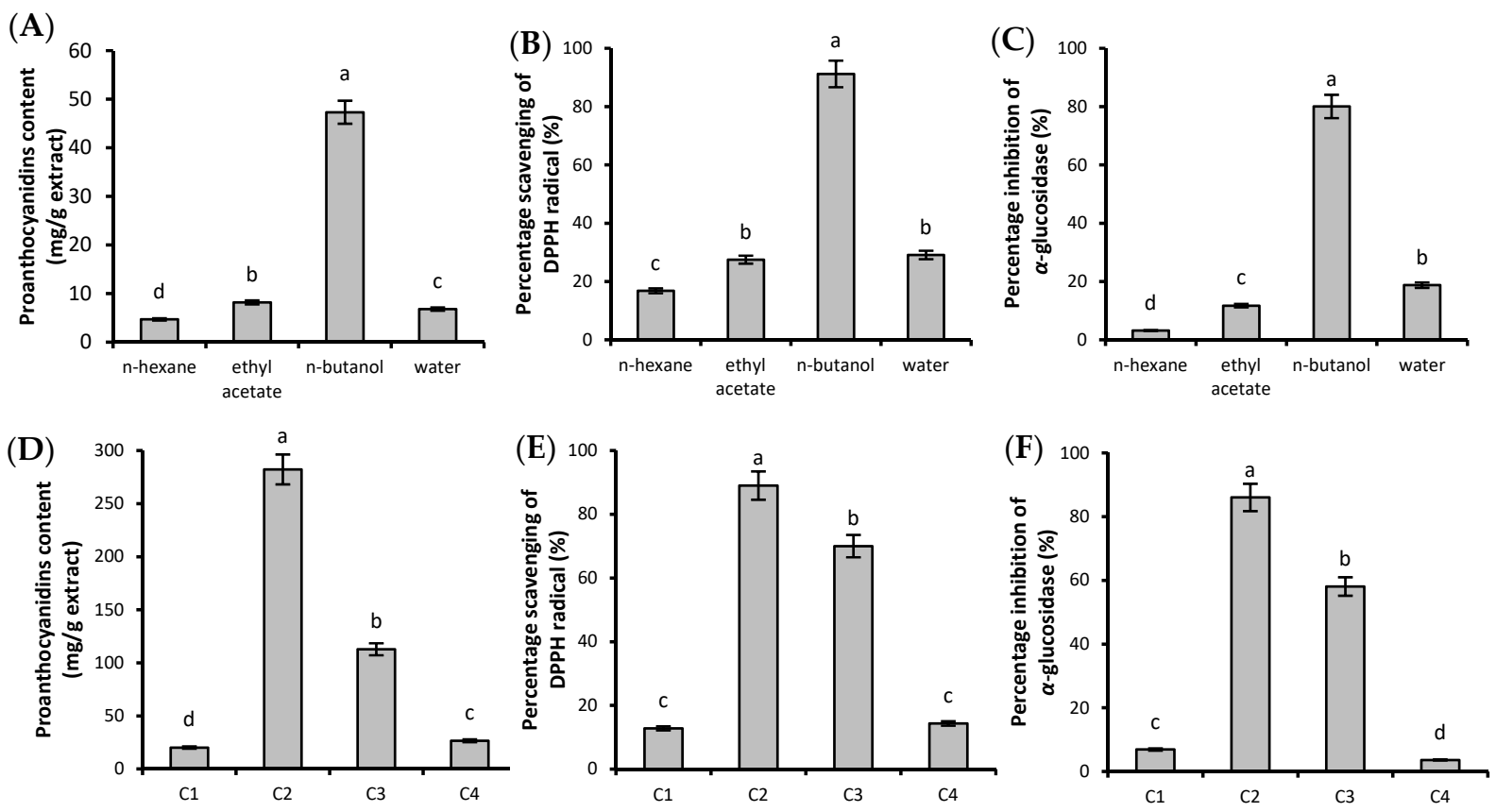

Figure 2. (A-F) Proanthocyanidin content, DPPH radical scavenging activity, and $\alpha$-glucosidase inhibitory activity of different fractions $(c=0.2 \mathrm{mg} / \mathrm{mL})$. Different letters above each bar within the same figure indicate significant differences $(p<0.05)$.

Table 2. The proanthocyanidin content, $\mathrm{IC}_{50}$ values of $\mathrm{DPPH}, \alpha$-glucosidase, and pancreatic lipase assay of fractions WRPs-1-WRPs-6.

\begin{tabular}{|c|c|c|c|c|}
\hline Fraction & $\begin{array}{c}\text { Proanthocyanidin Content } \\
\text { (mg/g Extract) }\end{array}$ & $\begin{array}{c}\mathrm{IC}_{50 / \mathrm{DPPH}} \\
(\mu \mathrm{g} / \mathrm{mL})\end{array}$ & $\begin{array}{c}\text { IC }_{50 / \alpha \text {-glucosidase }} \\
(\mu \mathrm{g} / \mathrm{mL})\end{array}$ & $\begin{array}{c}\mathrm{IC}_{50 / \text { pancreatic lipase }} \\
(\mu \mathrm{g} / \mathrm{mL})\end{array}$ \\
\hline WRPs-1 & $524.19 \pm 3.56^{\mathrm{e}}$ & $74.91 \pm 0.83^{c}$ & $316.07 \pm 1.08^{a}$ & $>2000$ \\
\hline WRPs-2 & $639.92 \pm 5.77^{c}$ & $59.57 \pm 1.52^{d}$ & $304.17 \pm 2.46^{b}$ & $>2000$ \\
\hline WRPs-3 & $863.81 \pm 8.02^{\mathrm{a}}$ & $34.29 \pm 0.78^{\mathrm{e}}$ & $289.04 \pm 3.11^{c}$ & $>2000$ \\
\hline WRPs-4 & $679.34 \pm 4.55^{b}$ & $36.73 \pm 0.96^{\mathrm{e}}$ & $257.20 \pm 3.85^{d}$ & $>2000$ \\
\hline WRPs-5 & $629.16 \pm 6.82^{c}$ & $35.44 \pm 1.02 \mathrm{e}$ & $117.72 \pm 1.45^{\mathrm{f}}$ & $>2000$ \\
\hline WRPs-6 & $567.20 \pm 5.76^{d}$ & $451.85 \pm 2.47^{\mathrm{a}}$ & $84.01 \pm 0.74 \mathrm{~g}$ & $1054.01 \pm 6.67^{\mathrm{a}}$ \\
\hline ascorbic acid & - & $100.05 \pm 0.94^{b}$ & - & - \\
\hline acarbose & - & - & $186.31 \pm 1.04 \mathrm{e}^{\mathrm{e}}$ & - \\
\hline orlistat & - & - & - & $15.45 \pm 0.14^{b}$ \\
\hline
\end{tabular}

\section{Data are expressed as mean $\pm \mathrm{SD}(n=3)$. Values with different letters in the same column are significantly different} $(p<0.05)$

\subsection{Structural Composition of Fractions WRPs-1-WRPs-6}

The reversed-phase UPLC chromatograms of fractions WRPs-1-WRPs-6 (Figure S2 in the Supplementary Materials) implied that they have distinctly different chemical compositions. The structural composition of fractions WRPs-1-WRPs- 6 was determined by using phloroglucinolysis, which has been proved to be an efficient method for structure analysis of proanthocyanidins $[18,19]$. In the degradation reaction, terminal units of proanthocyanidins are liberated as free flavan-3-ol monomers, while the extension units, released as electrophilic intermediates, are attacked by the nucleophile (phloroglucinol) to form the corresponding phloroglucinol adducts. The composition of the flavan-3-ol units and the mDP of the proanthocyanidins were determined by UPLC-LTQ-Orbitrap-MS analysis of the cleavage products. Figure 3 shows the reversed-phase UPLC chromatograms of the fractions WRPs-1-WRPs-6 after phloroglucinolysis. The major cleavage products detected were identified by comparing their retention times and MS data with those of authentic standards or literature data $[11,20]$, and results are listed in Table 3 . The WRPs were mainly composed of 
(+)-catechin (C), (-)-epicatechin (EC), and (-)-epigallocatechin (EGC) as terminal and extension units. The proportions of constitutive units and $\mathrm{mDP}$ of proanthocyanidins in each fraction were also calculated (Table 4). The terminal units of fractions WRPs-1-WRPs- 6 were mainly C and EC with proportions of $4.21 \pm 0.12-15.15 \pm 0.30 \%$ and $3.80 \pm 0.06-11.83 \pm 0.42 \%$, respectively. With respect to the extension units, EC with increased contents, from fractions WRPs-1 to WRPs-6, had the highest proportions ( $44.03 \pm 0.53-70.63 \pm 0.69 \%)$, followed by C $(15.79 \pm 0.21-22.89 \pm 0.26 \%)$, suggesting EC to be the major extension unit of WRPs. Compared with C and EC, EGC was found at much lower levels in the terminal and extension units $(1.70 \pm 0.04-9.55 \pm 0.33 \%$ and $2.87 \pm 0.08-3.87 \pm 0.10 \%$, respectively). The mDP gradually increased from fractions WRPs-1 to WRPs-6, with fraction WRPs-1 having a minimum of $2.66 \pm 0.04$ and fraction WRPs-6 having a maximum of $10.30 \pm 0.46$.
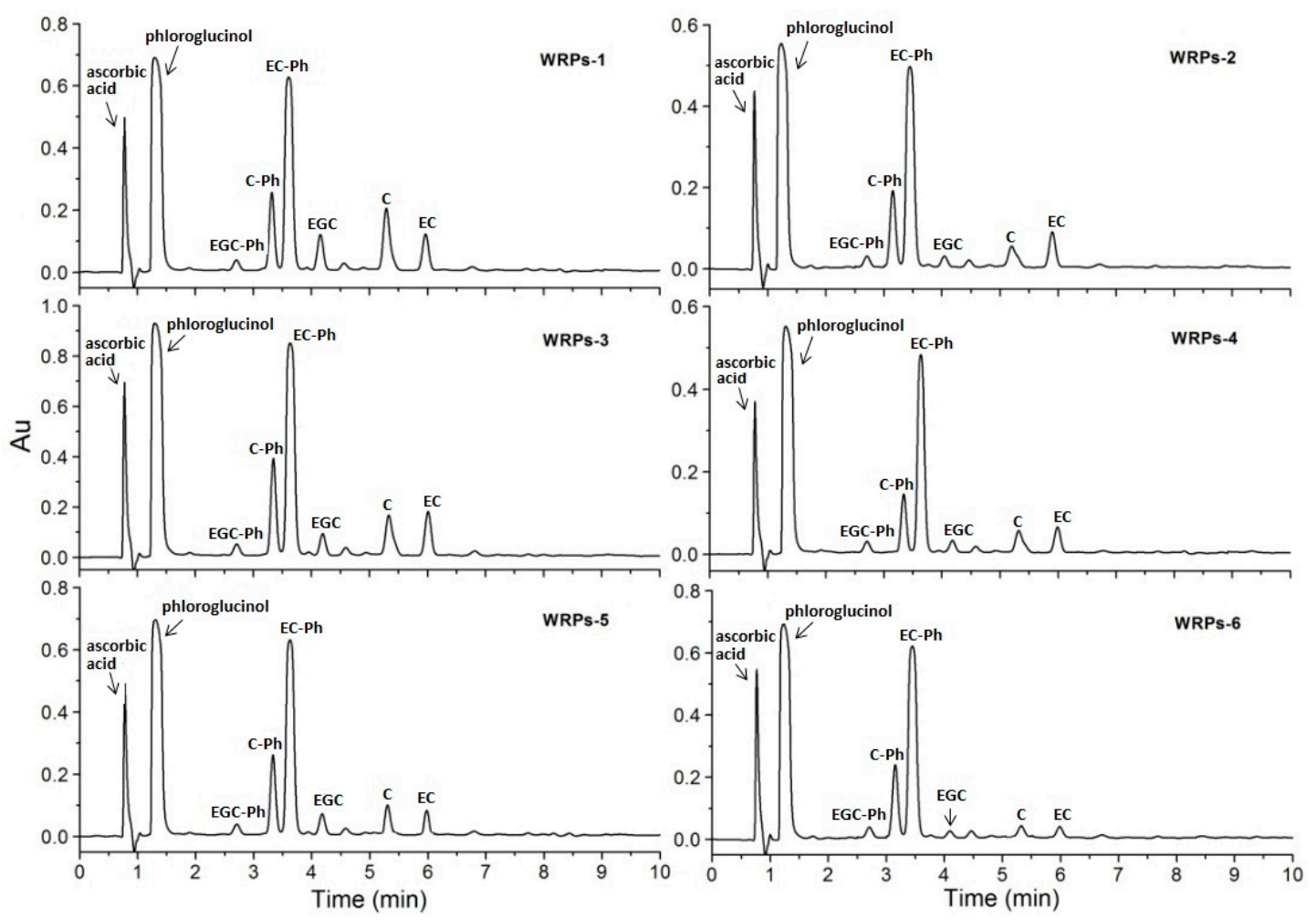

Figure 3. Reversed-phase UPLC chromatograms of fractions WRPs-1-WRPs- 6 after phloroglucinolysis at $280 \mathrm{~nm}$. Abbreviations: EGC-Ph, (-)-epigallocatechin-phloroglucinol derivative; $\mathrm{C}-\mathrm{Ph},(+)$-catechinphloroglucinol derivative; EC-Ph, (-)-epicatechin-phloroglucinol derivative; EGC, (-)-epigallocatechin; C, (+)-catechin; EC, (-)-epicatechin.

Table 3. Cleavage products of wild rice proanthocyanidins after phloroglucinolysis and their major MS data.

\begin{tabular}{cccccc}
\hline \multirow{2}{*}{$\begin{array}{c}\text { Retention } \\
\text { Time }(\mathbf{m i n})\end{array}$} & \multicolumn{3}{c}{$[\mathbf{M}+\mathbf{H}]^{+}(\mathbf{m} / \mathbf{z})$} & \multirow{2}{*}{ Fragment Ion $(\mathbf{m} / \mathbf{z})$} & Compound \\
\cline { 2 - 4 } & Measured & Calculated & Error $(\mathbf{p p m})$ & & \\
\hline 2.71 & 431.0970 & 431.0973 & -0.67 & $305.0655,263.0478$ & EGC-Ph \\
3.35 & 415.1024 & 415.1024 & -0.06 & $288.9869,271.1326,263.0480$ & C-Ph \\
3.67 & 415.1025 & 415.1024 & 0.27 & $288.9869,271.1326,263.0480$ & EC-Ph \\
4.18 & 307.0818 & 307.0812 & 1.89 & 181.0490 & EGC \\
5.30 & 291.0862 & 291.0863 & -0.56 & $273.0747,165.0544$ & C \\
6.00 & 291.0862 & 291.0863 & -0.56 & $273.0747,165.0544$ & EC \\
\hline
\end{tabular}

Abbreviations: EGC-Ph, (-)-epigallocatechin-phloroglucinol derivative; C-Ph, (+)-catechin-phloroglucinol derivative; EC-Ph, (-)-epicatechin-phloroglucinol derivative; EGC, (-)-epigallocatechin; $\mathrm{C},(+)$-catechin; EC, (-)-epicatechin. 
Table 4. Subunit composition (percent in moles) and mean degree of polymerization (mDP) of fractions WRPs-1-WRPs-6.

\begin{tabular}{|c|c|c|c|c|c|c|c|}
\hline Fraction & \multicolumn{3}{|c|}{ Terminal Unit (\%) } & \multicolumn{3}{|c|}{ Extension Unit (\%) } & mDP \\
\hline WRPs-1 & $15.15 \pm 0.30^{a}$ & $11.83 \pm 0.42^{\mathrm{a}}$ & $9.55 \pm 0.33^{\mathrm{a}}$ & $15.87 \pm 0.31^{\mathrm{d}}$ & $44.03 \pm 0.53^{\mathrm{e}}$ & $3.57 \pm 0.11^{b}$ & $2.66 \pm 0.04^{\mathrm{f}}$ \\
\hline WRPs-3 & $9.69 \pm 0.47^{b}$ & $6.55 \pm 0.13^{c}$ & $4.55 \pm 0.04^{b}$ & $20.43 \pm 0.24^{b}$ & $55.62 \pm 0.59^{c}$ & $3.16 \pm 0.12^{\mathrm{cd}}$ & $4.81 \pm 0.09^{\mathrm{d}}$ \\
\hline WRPs-4 & $7.52 \pm 0.48^{c}$ & $6.60 \pm 0.32^{c}$ & $3.19 \pm 0.17^{c}$ & $16.79 \pm 0.45^{c}$ & $63.03 \pm 0.80^{b}$ & $2.87 \pm 0.08^{\mathrm{e}}$ & $5.78 \pm 0.12^{\mathrm{c}}$ \\
\hline WRPs-5 & $6.01 \pm 0.28^{d}$ & $4.83 \pm 0.09 \mathrm{~d}$ & $4.45 \pm 0.12^{b}$ & $16.92 \pm 0.31^{c}$ & $64.71 \pm 0.65^{b}$ & $3.08 \pm 0.15^{\mathrm{d}}$ & $6.54 \pm 0.23^{b}$ \\
\hline
\end{tabular}

Data are expressed as mean \pm SD $(n=3)$. Abbreviations: C, (+)-catechin; EC, (-)-epicatechin; EGC, (-)-epigallocatechin; $\mathrm{C}-\mathrm{Ph},(+)$-catechin-phloroglucinol derivative; $\mathrm{EC}-\mathrm{Ph},(-)$-epicatechin-phloroglucinol derivative; EGC-Ph, (-)-epigallocatechin-phloroglucinol derivative. Values with different letters in the same column are significantly different $(p<0.05)$.

Upon comparing the aforementioned information with the bioactivities of fractions WRPs-1-WRPs-6, it is clear that the structure of WRPs greatly affects their bioactivity. The DPPH radical scavenging activity was the lowest in fraction WRPs- 6 with the largest $\mathrm{mDP}$, followed by fraction WRPs-1 with the smallest mDP, indicating that there was an increase and then a fall in DPPH radical scavenging activity as the mDP increased. Similarly, Jerez et al. found that for proanthocyanidins from the bark of Pinus radiata, there was an increase in DPPH radical scavenging activity up to $6.5 \mathrm{mDP}$ and then a fall in DPPH scavenging activity as mDP further increased (9.2-14.6 mDP) [21]. With respect to enzyme inhibitory activities, fraction WRPs-6, which had the largest mDP, showed the highest inhibitory activities against $\alpha$-glucosidase and pancreatic lipase. Previous reports also suggested that the $\alpha$-glucosidase inhibitory activity of proanthocyanidins from the leaves of Chamaecyparis obtusa var. formosana and pancreatic lipase inhibitory activity of proanthocyanidins from the fruits of Diospyros kaki both increased with mDP [22]. Therefore the mDP of WRPs is a significant determinant of their promising potential to be used as natural food antioxidants and enzyme inhibitors.

\section{Materials and Methods}

\subsection{Plant Materials and Chemicals}

Wild rice Z. latifolia was collected from Jiangling County, Jingzhou City, Hubei Province, China $\left(30^{\circ} 13^{\prime} 10^{\prime \prime} \mathrm{N} ; 112^{\circ} 34^{\prime} 5^{\prime \prime} \mathrm{E}\right)$, in September 2017 . The sample was obtained by manually harvesting mature plant tassels, drying and then dehulling them to obtain the seeds. The seeds were ground to a fine powder in a mechanical grinder and then sieved through a $0.45 \mathrm{~mm}$ sifter.

(+)-Catechin (C), (-)-epicatechin (EC), and (-)-epigallocatechin (EGC), DPPH (2,2-diphenyl-1picrylhydrazyl), $\alpha$-glucosidase (type I, from Saccharomyces cerevisiae), and pancreatic lipase (type II, from porcine pancreas) were purchased from Sigma-Aldrich Chemical Co., (St. Louis, MO, USA). Ascorbic acid, acarbose, and orlistat were obtained from Macklin Biochemical Co., Ltd. (Shanghai, China). Phloroglucinol was from Aladdin Reagents Co., Ltd. (Shanghai, China). HPLC and LC-MS grade solvents were bought from Sinopharm Chemical Reagent Co., Ltd. (Shanghai, China). The D101 macroporous resin and Sephadex LH-20 were from Solarbio Science \& Technology Co., Ltd. (Beijing, China) and GE Healthcare Bio-Sciences AB (Uppsala, Sweden), respectively. Precoated silica gel plates (GF254, Qingdao Marine Chemical Co., Ltd., Qingdao, China) were used for thin layer chromatography (TLC) analysis, and spots were visualized by spraying with anisaldehyde-sulfuric acid agent.

\subsection{Experimental Design to Set Up the Proanthocyanidins Extraction}

\subsubsection{Ultrasound-Assisted Extraction Procedure}

The WRPs were extracted using a KQ-2200DB ultrasonic cleaning bath (Kunshan Co., Ltd., Kunshan, China) and the temperature was preset before the extraction process. After extraction, the 
mixture was centrifuged at $3000 \times g$ for $20 \mathrm{~min}$, and the combined supernatants were used as the crude WRPs to determine the proanthocyanidin content.

\subsubsection{Experimental Design}

According to previous studies [23,24], a single factor experiment was firstly performed to investigate the effects of the concentration of aqueous ethanol (60, 70, 80, 90, and 100\%; EtOH \%, $v / v)$, the liquid-solid ratio $(20,30,40,50$, and $60 \mathrm{~mL} / \mathrm{g} ; \mathrm{v} / \mathrm{w})$, the extraction temperature $(30,40,50$, 60 , and $\left.70{ }^{\circ} \mathrm{C}\right)$, the ultrasonic power $(200,250,300,350$, and $400 \mathrm{~W})$, and the extraction time $(20,30$, 40,50 , and $60 \mathrm{~min}$ ) on the content of WRPs obtained. Subsequently, a BBD with four important variables at three levels, which were determined based on the single factor experimental results, was employed to optimize the extraction conditions. The combined effects of the four independent variables: the concentration of aqueous ethanol $\left(\mathrm{EtOH} \%, \mathrm{X}_{1}\right)$, the liquid-solid ratio $\left(\mathrm{mL} / \mathrm{g}, \mathrm{X}_{2}\right)$, the extraction temperature $\left({ }^{\circ} \mathrm{C}, \mathrm{X}_{3}\right)$, and the ultrasonic power $\left(\mathrm{W}, \mathrm{X}_{4}\right)$ were evaluated. The coded and uncoded (actual) levels of the independent variables are listed in Table S1 in the Supplementary Materials. The response variables were fitted to the following quadratic polynomial model:

$$
\mathbf{Y}=\beta_{0}+\sum_{\mathrm{i}=1}^{4} \beta_{\mathrm{i}} \mathrm{X}_{\mathrm{i}}+\sum_{\mathrm{i}=1}^{4} \beta_{\mathrm{ii}} \mathrm{X}_{\mathrm{i}}^{2}+\sum_{\mathrm{i}=1}^{3} \sum_{j=\mathrm{i}+1}^{4} \beta_{\mathrm{ij}} \mathrm{X}_{\mathrm{i}} \mathrm{X}_{\mathrm{j}}
$$

where $Y$ represents the response variable, WRPs content, $X_{i}$ and $X_{j}$ are the independent variables affecting the response, and $\beta_{0}, \beta_{\mathrm{i}}, \beta_{\mathrm{ii}}$, and $\beta_{\mathrm{ij}}$ are the regression coefficients of the model (intercept, linear, quadratic, and interaction terms, respectively).

The Design Expert Software (Version 8.0.6; Stat-Ease Inc., Minneapolis, MN, USA) was used for the experimental plan, data analysis, model generation, and determination of optimum conditions. The relationship between independent variables and responses was analyzed by response surface plots. Optimum conditions for UAE were calculated according to the desirability function.

\subsection{Partition and Purification of Crude WRPS}

Using a previously described method for preparing proanthocyanidins [25], the crude WRPs obtained by UAE were successively partitioned with n-hexane, ethyl acetate, n-butanol, and water (three times for each) to yield soluble fractions of n-hexane (yield 18.17\%, w/w), ethyl acetate (yield 11.62\%), n-butanol (yield 26.08\%), and water (yield 44.13\%), respectively. The n-butanol soluble fraction was then subjected to a D101 macroporous adsorption resin column $(16 \times 300 \mathrm{~mm})$, eluting with deionized water $(100 \mathrm{~mL})$, and $10 \%, 20 \%, 30 \%, 40 \%, 50 \%, 60 \%, 70 \%, 80 \%, 90 \%$, and $100 \%$ aqueous ethanol solution $(\mathrm{EtOH} \%, v / v, 250 \mathrm{~mL}$ for each, $2 \mathrm{~mL} / \mathrm{min})$. The effluents were collected sequentially and then combined to obtain four fractions (fractions C1-C4) based on a TLC analysis. In general, the water eluent was collected as fraction C1 (yield 33.51\%, w/w). The 10-30\% ethanol eluents were combined as fraction C2 (yield 20.35\%). The eluents of 40-60\% ethanol gave fraction C3 (yield 8.06\%). The 70-100\% ethanol eluents produced fraction C4 (yield 27.23\%).

\subsection{Fractionation of WRPS}

The proanthocyanidin-rich fractions C2 and C3 were combined and then loaded onto a Sephadex LH-20 column $(10 \times 800 \mathrm{~mm})$. The eluting solvent gradient used was based on that described by Wei et al. [26], with slight modifications. In brief, the column was washed with deionized water $(150 \mathrm{~mL})$, followed by methanol-water $(40: 60, v / v ; 150 \mathrm{~mL})$ to remove sugars, glycosides, and monomeric phenols [27], and then sequentially eluted with methanol-water (60:40, v/v; $100 \mathrm{~mL})$, methanol-water $(75: 25, v / v ; 100 \mathrm{~mL})$, methanol-water $(90: 10, v / v ; 100 \mathrm{~mL})$, acetone-methanol-water $(10: 80: 10, v / v$; $100 \mathrm{~mL})$, acetone-methanol-water $(20: 65: 15, v / v ; 50 \mathrm{~mL})$, acetone-methanol-water $(30: 40: 30, v / v ; 50 \mathrm{~mL})$, and finally acetone-water $(70: 30, v / v ; 100 \mathrm{~mL})$, at a flow rate of $0.15 \mathrm{~mL} / \mathrm{min}$. The effluents were collected using a fraction collector ( $3 \mathrm{~mL}$ per tube). Following a TLC analysis using methanol/ethyl 
acetate/isopropanol/formic acid (1:10:1:1 and 1:7:1:1, v/v) as the developing solvents, six fractions were pooled and concentrated: WRPs-1 (effluents of methanol-water 60:40 and 75:25), WRPs-2 (effluents of methanol-water 90:10), WRPs-3 (effluents of methanol-water 90:10 and acetone-methanol-water 10:80:10), WRPs-4 (effluents of acetone-methanol-water 10:80:10 and 20:65:15), WRPs-5 (effluents of acetone-methanol-water 30:40:30), and WRPs-6 (effluents of acetone-water 70:30). The yields for fractions WRPs-1-WRPs-6 were 26.43\%, 21.22\%, 14.30\%, 6.49\%, 13.55\%, and 8.87\% (w/w), respectively.

\subsection{Acid-Catalysis in the Presence of Phloroglucinol (Phloroglucinolysis)}

Phloroglucinolysis of the isolated fractions WRPs-1-WRPs-6 was performed based on an earlier study [18]. Briefly, $5 \mathrm{mg}$ of sample was reacted in $1 \mathrm{~mL}$ of $0.1 \mathrm{~N} \mathrm{HCl}$ in methanol containing $50 \mathrm{~g} / \mathrm{L}$ phloroglucinol and $10 \mathrm{~g} / \mathrm{L}$ ascorbic acid in a stoppered test tube. The reaction mixture was heated at $50{ }^{\circ} \mathrm{C}$ for $20 \mathrm{~min}$, after which $5 \mathrm{~mL}$ of $40 \mathrm{mM}$ aqueous sodium acetate was added to stop the reaction. The cleavage products were immediately analyzed by UPLC-LTQ-Orbitrap-MS.

\subsection{UPLC-LTQ-Orbitrap-MS Analysis}

A Waters ACQUITY H-CLASS UPLC instrument with a photo-diode array and an autosampler (Waters, Milford, MA, USA), coupled with a linear ion trap quadrupole Orbitrap XL mass spectrometer (Thermo Scientific, San Jose, CA, USA), was used to analyze the cleavage products. For the analysis, $2 \mu \mathrm{L}$ of sample was injected onto a Waters ACQUITY UPLC BEH C18 column $(1.7 \mu \mathrm{m}, 2.1 \times 50 \mathrm{~mm})$ and eluted with a mobile phase gradient consisting of $0.1 \%(v / v)$ acetic acid in acetonitrile (solvent $\mathrm{A}$ ) and $0.1 \%(v / v)$ acetic acid in water (solvent $\mathrm{B}$ ), at a flow rate of $0.3 \mathrm{~mL} / \mathrm{min}$. The solvent system was as follows: 0-4 $\min , 5-10 \%$ A; 4-6 $\min , 10-15 \%$ A; 6-8 $\mathrm{min}, 15-60 \%$ A; 8-9 $\mathrm{min}, 60-90 \%$ A; and 9-10 min, 90-95\% A.

For mass detection, an electrospray ionization source was operated in positive mode with a scan range from $m / z 150$ to 1500 . The capillary temperature was $350{ }^{\circ} \mathrm{C}$. Nitrogen was used as the sheath gas and auxiliary gas, and the gas flow was set at 30 and 5 arbitrary units, respectively. The spray voltage was $4000 \mathrm{~V}$. The collision energy was 35\% to adjust for collision-induced dissociation for the best performance. The Xcalibur 2.1 software (Thermo Scientific, San Jose, CA, USA) was used for data analysis.

The identification of C, EC, EGC, and the corresponding phloroglucinol adducts was achieved by comparing their UPLC retention times and MS data with those of authentic standards or literature data. C, EC, and EGC were quantified based on their standards. For quantitation of the phloroglucinol adducts, the respective flavan-3-ol monomers were used as the standards. With this procedure, the phloroglucinol adducts were assumed to have the same molar absorptivities as their respective flavan-3-ol monomers $[18,28]$. To calculate the $\mathrm{mDP}$ of the proanthocyanidins, the sum of all subunits (flavan-3-ol monomers and phloroglucinol adducts, in moles), was divided by the sum of all flavan-3-ol monomers (in moles).

\subsection{Determination of Proanthocyanidin Content}

The proanthocyanidin content was measured using a modified vanillin- $\mathrm{H}_{2} \mathrm{SO}_{4}$ method [29]. Briefly, $20 \mu \mathrm{L}$ of the sample was mixed with $100 \mu \mathrm{L}$ of vanillin methanol solution $(30 \mathrm{~g} / \mathrm{L})$ and $100 \mu \mathrm{L}$ of $\mathrm{H}_{2} \mathrm{SO}_{4}$ methanol solution $(30 \%, v / v)$. (+)-Catechin was used as a reference. After incubation at room temperature for $5 \mathrm{~min}$ in the dark, the absorbance at $500 \mathrm{~nm}$ was measured using a Multiskan GO microplate spectrophotometer (Thermo Scientific, San Jose, CA, USA). The results for the crude WRPs and the isolated fractions were expressed as milligram (+)-catechin equivalents per gram of rice $(\mathrm{mg} / \mathrm{g}$ rice) and milligram $(+)$-catechin equivalents per gram of extract $(\mathrm{mg} / \mathrm{g}$ extract), respectively. 


\subsection{DPPH Radical Scavenging Assay}

The DPPH radical scavenging activity was evaluated using the method described by Yuan et al. [30], with ascorbic acid as the positive control. The percentage of scavenging was calculated according to the following equation:

$$
\text { Percentage scavenging of DPPH radical }(\%)=\left(1-\mathrm{A}_{\text {sample }} / \mathrm{A}_{\text {control }}\right) \times 100
$$

where $\mathrm{A}_{\text {sample }}$ represents the absorbance of the DPPH solution in the presence of the sample and $\mathrm{A}_{\text {control }}$ is the absorbance of the DPPH solution without sample (which was replaced by the solvent). The corresponding $\mathrm{IC}_{50}$ value, defined as the concentration of extract required to scavenge $50 \%$ of the DPPH radicals, was also calculated, and the result was expressed as micrograms extract per milliliter solvent $(\mu \mathrm{g} / \mathrm{mL})$.

\section{9. $\alpha$-Glucosidase Inhibition Assay}

The $\alpha$-glucosidase inhibition assay was carried out according to a previously reported method [31], with some modifications. Briefly, $10 \mu \mathrm{L}$ of the test sample in DMSO was mixed with $620 \mu \mathrm{L}$ of phosphate buffered saline (PBS; $0.1 \mathrm{M}, \mathrm{pH}$ 6.9) after which $10 \mu \mathrm{L}$ of $\alpha$-glucosidase (2 U/mL) in PBS was added and incubated at $37^{\circ} \mathrm{C}$ for $10 \mathrm{~min}$. Following this, $200 \mu \mathrm{L}$ of $6 \mathrm{mM}$-nitrophenyl $\alpha$-D-glucopyranoside in PBS was added and incubated at $37^{\circ} \mathrm{C}$ for another $20 \mathrm{~min}$. The reaction was terminated by adding $1 \mathrm{~mL}$ of $1 \mathrm{M}$ sodium carbonate aqueous solution and the absorbance at $400 \mathrm{~nm}$ was measured. Acarbose was used as the positive control. The percentage inhibition was calculated as follows:

$$
\begin{gathered}
\text { Percentage inhibition of } \alpha \text {-glucosidase }(\%)=\left[1-\left(\mathrm{A}_{\text {sample }}-\mathrm{A}_{\text {background }}\right) /\left(\mathrm{A}_{\text {control }}-\right.\right. \\
\left.\left.\mathrm{A}_{\text {background }}\right)\right] \times 100
\end{gathered}
$$

where $\mathrm{A}_{\text {sample }}$ represents the absorbance of the test sample, $\mathrm{A}_{\text {control }}$ is the absorbance of the control solution without sample (which was replaced by DMSO), and $\mathrm{A}_{\text {background }}$ is the absorbance of the background solution without $\alpha$-glucosidase (which was replaced by PBS). The $\mathrm{IC}_{50}$ value $(\mu \mathrm{g} / \mathrm{mL})$ as similarly defined for the DPPH radical was also determined.

\subsection{Pancreatic Lipase Inhibition Assay}

The pancreatic lipase activity was measured using a previous method [31], with some modifications. Briefly, $10 \mu \mathrm{L}$ of the test sample in DMSO was added to $500 \mu \mathrm{L}$ of Tris- $\mathrm{HCl}$ buffer $(0.1 \mathrm{M}, \mathrm{pH} 8.0)$, after which $200 \mu \mathrm{L}$ of pancreatic lipase $(2 \mathrm{mg} / \mathrm{mL})$ in Tris- $\mathrm{HCl}$ buffer was added and incubated at $37^{\circ} \mathrm{C}$ for $15 \mathrm{~min}$. Following this, $200 \mu \mathrm{L}$ of $12.5 \mathrm{mM} p$-nitrophenyl butyrate in Tris- $\mathrm{HCl}$ buffer was added and incubated at $37^{\circ} \mathrm{C}$ for $20 \mathrm{~min}$. The absorbance at $400 \mathrm{~nm}$ was measured and orlistat was used as the positive control. The percentage inhibition of pancreatic lipase was calculated as follows:

$$
\begin{gathered}
\text { Percentage inhibition of pancreatic lipase }(\%)=\left[1-\left(\mathrm{A}_{\text {sample }}-\mathrm{A}_{\text {background }}\right) /\left(\mathrm{A}_{\text {control }}-\right.\right. \\
\left.\left.\mathrm{A}_{\text {background }}\right)\right] \times 100
\end{gathered}
$$

where $A_{\text {sample }}$ represents the absorbance of the test sample, $A_{\text {control }}$ is the absorbance of the control solution without the sample (which was replaced by DMSO), and $\mathrm{A}_{\text {background }}$ is the absorbance of the background solution without pancreatic lipase (which was replaced by Tris- $\mathrm{HCl}$ ). The $\mathrm{IC}_{50}$ value $(\mu \mathrm{g} / \mathrm{mL})$ was calculated.

\subsection{Statistical Analysis}

All results are the averages of at least three assay replicates and are expressed as the mean \pm standard deviation (SD). Statistical analysis was performed using the SPSS 19.0 software (SPSS Inc., Chicago, IL, USA). $p$-Values $<0.05$ were considered to be statistically significant. 


\section{Conclusions}

In the present study, an optimized UAE was applied to extract proanthocyanidins from Chinese wild rice with high yield. Six specific fractions with $\mathrm{mDP}$ in increasing order were obtained after partition, purification, and fractionation of crude WRPs. Fractions WRPs-1-WRPs-5 possessed excellent DPPH radical scavenging activity, and fraction WRPs- 6 with the highest mDP had $\alpha$-glucosidase and pancreatic lipase inhibitory effects. These findings provide, for the first time, useful information on the structures and potential bioactivities of different WRP fractions. The high proanthocyanidin contents and the potential role of the different WRP fractions in oxidation resistance and management of diabetes and obesity make them worthy of further consideration as functional food ingredients or nutraceuticals. Future in vivo study on these beneficial effects will be carried out to facilitate the applications of WRPs.

Supplementary Materials: The following are available online, Table S1: Box-Behnken design with coded and actual values for the extraction conditions and response values for the content of wild rice proanthocyanidins. Figure S1: Effects of different extraction parameters on the content of wild rice proanthocyanidins in the single factor experiment. Figure S2: Reversed-phase UPLC chromatograms of fractions WRPs-1-WRPs-6 eluted from Sephadex LH-20 column at $280 \mathrm{~nm}$.

Author Contributions: Z.-F.Z. and M.-J.C. conceived and designed the experiments. M.-J.C. and N.Y. performed the experiments. Y.-M.D. and X.-M.L. collected the Chinese wild rice sample. M.-J.C. and F.-Z.W. analyzed the data. M.-J.C. and Y.-M.D. wrote the manuscript. All authors read and approved the final manuscript.

Funding: This research was funded by the Agricultural Science and Technology Innovation Program, grant number ASTIP-TRIC05, the Postdoctoral Applied Research Project Fund of Qingdao, and the Science Foundation for Young Scholars of the Tobacco Research Institute of the Chinese Academy of Agricultural Sciences, grant number 2018A01.

Conflicts of Interest: The authors declare no conflict of interest.

\section{References}

1. Sumczynski, D.; Koubová, E.; Šenkárová, L.; Orsavová, J. Rice flakes produced from commercial wild rice: Chemical compositions, vitamin B compounds, mineral and trace element contents and their dietary intake evaluation. Food Chem. 2018, 264, 386-392. [CrossRef] [PubMed]

2. Yan, N.; Du, Y.M.; Liu, X.M.; Chu, C.; Shi, J.; Zhang, H.B.; Liu, Y.H.; Zhang, Z.F. Morphological characteristics, nutrients, and bioactive compounds of Zizania latifolia, and health benefits of its seeds. Molecules 2018, 23, 1561. [CrossRef] [PubMed]

3. Zhang, H.; Cao, P.; Agellon, L.B.; Zhai, C.K. Wild rice (Zizania latifolia (Griseb) Turcz) improves the serum lipid profile and antioxidant status of rats fed with a high fat/cholesterol diet. Brit. J. Nutr. 2009, 102, 1723-1727. [CrossRef]

4. Sumczynski, D.; Kotásková, E.; Orsavová, J.; Valášek, P. Contribution of individual phenolics to antioxidant activity and in vitro digestibility of wild rices (Zizania aquatica L.). Food Chem. 2017, 218, 107-115. [CrossRef]

5. Han, S.F.; Zhang, H.; Zhai, C.K. Protective potentials of wild rice (Zizania latifolia (Griseb) Turcz) against obesity and lipotoxicity induced by a high-fat/cholesterol diet in rats. Food Chem. Toxicol. 2012, 50, $2263-2269$. [CrossRef]

6. Zhai, C.K.; Lu, C.M.; Zhang, X.Q.; Sun, G.J.; Lorenz, K.J. Comparative study on nutritional value of Chinese and North American wild rice. J. Food. Compos. Anal. 2001, 14, 371-382. [CrossRef]

7. Chu, M.J.; Liu, X.M.; Yan, N.; Wang, F.Z.; Du, Y.M.; Zhang, Z.F. Partial purification, identification, and quantitation of antioxidants from wild rice (Zizania latifolia). Molecules 2018, 23, 2782. [CrossRef]

8. Qiu, Y.; Liu, Q.; Beta, T. Antioxidant activity of commercial wild rice and identification of flavonoid compounds in active fractions. J. Agric. Food Chem. 2009, 57, 7543-7551. [CrossRef]

9. Zhou, P.Y.; Zhang, L.M.; Li, W.; Zhang, S.T.; Luo, L.X.; Wang, J.; Sun, B.S. In vitro evaluation of the anti-digestion and antioxidant effects of grape seed procyanidins according to their degrees of polymerization. J. Funct. Foods 2008, 49, 85-95. [CrossRef] 
10. Li, S.Y.; Xiao, J.; Chen, L.; Hu, C.L.; Chen, P.; Xie, B.J.; Sun, Z.D. Identification of A-series oligomeric procyanidins from pericarp of Litchi chinensis by FT-ICR-MS and LC-MS. Food Chem. 2012, 135, 31-38. [CrossRef]

11. Zhang, S.T.; Li, L.X.; Cui, Y.; Luo, L.X.; Li, Y.Y.; Zhou, P.Y.; Sun, B.S. Preparative high-speed counter-current chromatography separation of grape seed proanthocyanidins according to degree of polymerization. Food Chem. 2017, 219, 399-407. [CrossRef]

12. Nunes, M.A.; Pimentel, F.; Costa, A.S.G.; Alves, R.C.; Oliveira, M.B.P.P. Cardioprotective properties of grape seed proanthocyanidins: An update. Trends Food Sci. Technol. 2016, 57, 31-39. [CrossRef]

13. Zhu, W.; Jia, Y.Y.; Peng, J.M.; Li, C.M. Inhibitory effect of persimmon tannin on pancreatic lipase and the underlying mechanism in vitro. J. Agric. Food Chem. 2018, 66, 6013-6021. [CrossRef]

14. Liu, Z.Z.; Mo, K.L.; Fei, S.M.; Zu, Y.G.; Yang, L. Efficient approach for the extraction of proanthocyanidins from Cinnamomum longepaniculatum leaves using ultrasonic irradiation and an evaluation of their inhibition activity on digestive enzymes and antioxidant activity in vitro. J. Sep. Sci. 2017, 40, 3100-3113. [CrossRef]

15. Zhang, H.W.; Yang, Y.M.; Ma, C.M. Structures and antioxidant and intestinal disaccharidase inhibitory activities of A-type proanthocyanidins from peanut skin. J. Agric. Food Chem. 2013, 61, 8814-8820. [CrossRef]

16. Tang, Y.; Zhang, B.; Li, X.H.; Chen, P.X.; Zhang, H.; Liu, R.H.; Tsao, R. Bound phenolics of quinoa seeds released by acid, alkaline, and enzymatic treatments and their antioxidant and alpha-glucosidase and pancreatic lipase inhibitory effects. J. Agric. Food Chem. 2016, 64, 1712-1719. [CrossRef]

17. Odabaş, H.İ.; Koca, I. Application of response surface methodology for optimizing the recovery of phenolic compounds from hazelnut skin using different extraction methods. Ind. Crop. Prod. 2016, 91, 114-124. [CrossRef]

18. Kennedy, J.A.; Jones, G.P. Analysis of proanthocyanidin cleavage products following acid-catalysis in the presence of excess phloroglucinol. J. Agric. Food Chem. 2001, 49, 1740-1746. [CrossRef]

19. Jakobek, L.; García-Villalb, R.; Tomás-Barberán, F.A. Polyphenolic characterisation of old local apple varieties from Southeastern European region. J. Food Compos. Anal. 2013, 31, 199-211. [CrossRef]

20. Karonen, M.; Leikas, A.; Loponen, J.; Sinkkonen, J.; Ossipov, V.; Pihlaja, K. Reversed-phase HPLC-ESI/MS analysis of birch leaf proanthocyanidins after their acidic degradation in the presence of nucleophiles. Phytochem. Anal. 2007, 18, 378-386. [CrossRef]

21. Jerez, M.; Tourino, S.; Sineiro, J.; Lluis Torres, J.; Jose Nunez, M. Procyanidins from pine bark: Relationships between structure, composition and antiradical activity. Food Chem. 2007, 104, 518-527. [CrossRef]

22. Hsu, C.Y.; Lin, G.M.; Lin, H.Y.; Chang, S.T. Characteristics of proanthocyanidins in leaves of Chamaecyparis obtusa var. formosana as strong $\alpha$-glucosidase inhibitors. J. Sci. Food Agric. 2018, 98, 3806-3814. [CrossRef]

23. Chemat, F.; Rombaut, N.; Sicaire, A.G.; Meullemiestre, A.; Fabiano-Tixier, A.S.; Abert-Vian, M. Ultrasound assisted extraction of food and natural products. Mechanisms, techniques, combinations, protocols and applications. A review. Ultrason. Sonochem. 2017, 34, 540-560. [CrossRef]

24. Li, S.Y.; Yang, Y.J.; Li, J.S.; Zhu, Z.Z.; Lorenzo, J.M.; Barba, F.J. Increasing yield and antioxidative performance of Litchi pericarp procyanidins in baked food by ultrasound-assisted extraction coupled with enzymatic treatment. Molecules 2018, 23, 2089. [CrossRef]

25. Lin, G.M.; Lin, H.Y.; Hsu, C.Y.; Chang, S.T. Structural characterization and bioactivity of proanthocyanidins from indigenous cinnamon (Cinnamomum osmophloeum). J. Sci. Food Agric. 2016, 96, 4749-4759. [CrossRef]

26. Wei, S.D.; Zhou, H.C.; Lin, Y.M. Antioxidant activities of fractions of polymeric procyanidins from stem bark of Acacia confusa. Int. J. Mol. Sci. 2011, 12, 1146-1160. [CrossRef]

27. Zhou, H.C.; Lin, Y.M.; Wei, S.D.; Tam, N.F.Y. Structural diversity and antioxidant activity of condensed tannins fractionated from mangosteen pericarp. Food Chem. 2011, 129, 1710-1720. [CrossRef]

28. Bindon, K.A.; Smith, P.A.; Holt, H.; Kennedy, J.A. Interaction between grape-derived proanthocyanidins and cell wall material. 2. Implications for vinification. J. Agric. Food Chem. 2010, 58, 10736-10746. [CrossRef]

29. Hsieh, C.Y.; Chang, S.T. Antioxidant activities and xanthine oxidase inhibitory effects of phenolic phytochemicals from Acacia confusa twigs and branches. J. Agric. Food Chem. 2010, 58, 1578-1583. [CrossRef] 
30. Yuan, Y.; Xu, X.; Jing, C.L.; Zou, P.; Zhang, C.S.; Li, Y.Q. Microwave assisted hydrothermal extraction of polysaccharides from Ulva prolifera: Functional properties and bioactivities. Carbohyd. Polym. 2018, 181, 902-910. [CrossRef]

31. Rahman, M.J.; Camargo, A.C.; Shahidi, F. Phenolic and polyphenolic profiles of chia seeds and their in vitro biological activities. J. Funct. Foods 2017, 35, 622-634. [CrossRef]

Sample Availability: Not available.

(C) 2019 by the authors. Licensee MDPI, Basel, Switzerland. This article is an open access article distributed under the terms and conditions of the Creative Commons Attribution (CC BY) license (http://creativecommons.org/licenses/by/4.0/). 